\title{
Changes in body weight and blood pressure among women using Depo-Provera injection in Northwest Ethiopia
}

\author{
Muluken Fekadie Zerihun ${ }^{*}$, Tabarak Malik ${ }^{1}$, Yohannes Mulu Ferede ${ }^{2}$, Tesfahun Bekele ${ }^{1}$ and Yigizie Yeshaw ${ }^{3}$
}

\begin{abstract}
Objectives: Depo-Provera is an injectable contraceptive method containing medroxyprogesterone acetate. It has some adverse effects like changes in menstrual pattern, loss in bone mineral density and risk of weight gain. Therefore, this study is aimed at to investigate the effects of Depo-Provera on body weight and blood pressure among Ethiopian women. Institution based cross-sectional study design was conducted from January 2017 to April 2017. Data were analyzed using SPSS version 21 software. Paired $t$ test, independent t-test and ANOVA were used to evaluate the presence of mean difference and relationship between changes in variables and duration of use of DepoProvera. P-value $\leq 0.05$ were considered as statistically significant.

Results: The mean weight and body mass index (BMI) of Depo-Provera users were increased significantly $(p=0.02$ for mean body weight and $p=0.019$, for body mass index). There was no significant difference in mean arterial blood pressure (MAP) of Depo-Provera users compared to controls or their respective pretreatment value ( $p$-value $=0.85$ for Depo-Provera users and 0.67 for non-users). The finding of this study revealed that there is an increased weight gain and BMI among Depo-Provera users compared to non-users, which really requires attention of health professionals and other stake holders.
\end{abstract}

Keywords: Body weight, Depo Provera, Blood pressure, Ethiopia

\section{Introduction}

Worldwide average fertility rate is 1.7 in developed countries compared to 4.6 children per woman in least developed countries [1]. In Ethiopia average total fertility rate is 4.1 , which is among the highest in the world $[2,3]$. Increased use of family planning methods help to bring these figures down to low levels in less developed countries like Ethiopia.

In Ethiopia, the family planning service is provided by both governmental and NGO health facilities, including hospitals, clinics, health centers, and health stations [4]. Among the different methods of family planning, injectable hormonal contraceptives; Depo-Provera (Depomedroxyprogesterone acetate) are the most popular

\footnotetext{
*Correspondence: mulukenfekadie@gmail.com

${ }^{1}$ Department of Biochemistry, School of Medicine, College of Medicine and Health Sciences, University of Gondar, Gondar, Ethiopia

Full list of author information is available at the end of the article
}

contraceptive methods in Sub-Saharan Africa including Ethiopia, contributing to about $40 \%$ of the total method mix in the region [5]. Depo-Provera is among a highly effective, convenient non-daily injectable hormonal contraceptive option with a very low failure rate that has been available worldwide for many years. The recommended dose of this contraceptive is $150 \mathrm{mg}$, administered by deep intramuscular (IM) injection at the interval of 3 months using strict aseptic technique in the gluteal or deltoid muscle [6,7]. Side effects of this contraceptive method include: changes in menstrual patterns, loss of bone mineral density and risk of weight gain.

Prior studies have demonstrated the association between Depo-Provera with both weight gain $[8,9]$ and blood pressure [10]. On the other hand, another study reported that Depo-Provera injections did not cause a significant increase in body weight and blood pressure [6]. Since the previous studies performed among different ethnic groups showed diverse results and available data 
on this topic which are mostly from developed countries, this study was aimed to investigate the effects of DepoProvera on body weight and blood pressure among Ethiopian women.

\section{Main text \\ Methods \\ Study area and period}

This study was conducted at Azezo Health Center, Gondar, Northwest Ethiopia. It serves for a total population of more than 25,000 individuals per year. The study was conducted from January 2017 to April 2017.

Study design: Institution-based comparative cross-sectional study design was employed.

\section{Source and study population}

All Depo-Provera users between 18 and 45 years of ages and the age matched non-Depo Provera users were the source population. Depo-Provera users between 18 and 45 years of age and age matched non-Depo Provera users who were present during the study period were the study population.

\section{Inclusion and exclusion criteria}

Women with chronic diseases like Diabetes mellitus and Hypertension and those who took medications known to affect body weight and blood pressure were excluded.

\section{Sample size determination}

The sample size for this study was determined by doublepopulation formula: assuming $95 \%$ confidence interval, $80 \%$ power and by using the highest standard deviation. Systematic random sampling technique was used to select 50 healthy women who had been using DepoProvera for at least 6 months and convenient sampling technique was used to recruit another 50 healthy agematched ( \pm 2 years) controls who visited the health centers accompanying the patients during the study period.

\section{Variables of the study}

Dependent variable: Body weight, body mass index and blood pressure.

Independent variables: Age, duration of use of Depo Provera.

\section{Data collection instrument and procedure}

Structured pretested interviewer administered questionnaire was used to collect data. The questionnaire was prepared in English first and translated to Amharic and then, retranslated back to English by another person to check its consistency. Blood pressure was measured using recently calibrated standardized sphygmomanometer. The height measurement was also taken using stadiometer on flooring that is not carpeted and against a flat surface such as a wall with no molding and by removing the shoes, bulky clothing, hair ornaments, and unbraid hair that interferes with the measurement. The weight $(\mathrm{Kg})$ of study participants was taken using a mechanical scale or balance.

The Mean Arterial Blood Pressure (MAP) was calculated by using the formula, MAP $=$ Diastolic Blood Pressure (DBP) $+1 / 3$ (Systolic Blood Pressure-DBP). Body Mass Index (BMI) was computed by dividing weight $(\mathrm{Kg})$ to the square of height in meter. The change in body weight, BMI and MAP of Depo-Provera users were calculated as the difference between initial body weight, $\mathrm{BMI}$ and MAP on the first day of injection, recorded by the health care providers and the final weight, BMI and MAP taken at their visit during study period.

\section{Data quality control}

Training was given for data collectors and pretest was also done. During data collection, data collectors were closely supervised by the supervisor and principal investigator on daily basis. Then after appropriate data clean up and correction was done just before analysis.

\section{Data processing and analysis}

Data were entered into Epi Data version 3.1 and exported to Statistical package for Social Sciences (SPSS) version 21 for analysis. Descriptive statistics such as mean, standard deviation (SD) and range were calculated. Paired t-test was used to evaluate change in body weight, BMI and blood pressure of Depo-Provera users. Independent $\mathrm{t}$-test was also used to compare the results of blood pressure of Depo-Provera users and their age-matched control group. One-way ANOVA was used to identify the variation of variables in relation to the duration of use of Depo-Provera. Pearson's correlation-test was used to evaluate the association between the variables. All values were quoted as the mean $\pm S D$, p-values of $\leq 0.05$ were considered to be statistically significant.

\section{Results}

\section{Description of study participants}

A total of 100 study participants (50 Depo-Provera users and 50 controls) were included in the study. The mean age of Depo-Provera users was $27.54 \pm 5.63$ years and $27.44 \pm 5.02$ years for control group. The mean BMI $\left(\mathrm{Kg} / \mathrm{m}^{2}\right)$ was $22.05 \pm 3.10$ for Depo-Provera users and $21.55 \pm 3.05$ for that of controls.

\section{Magnitude and determinants of change in body weight and body mass index}

This study indicates that Depo-Provera caused a significant weight gain. Weight gain varies from 1 to $14 \mathrm{~kg}$. 
Excessive weight gain ( $\geq 10 \%)$ was observed in 9 (18\%) of Depo-Provera users. Moreover, Depo-Provera users showed significant increase ( $\mathrm{p}$-value-0.02) in BMI compared to their respective pretreatment value (Table 1 ). The mean change in BMI among Depo-Provera users was $0.67(+3.13 \%)$. The maximum increment of BMI among Depo-Provera users was $5.9 \mathrm{~kg} / \mathrm{m}^{2}$. However, student's paired t-test showed significant changes in mean weight and BMI among Depo-Provera users, the one-way ANOVA did not show significant $(p>0.05)$ changes in mean weight and BMI between groups of Depo-Provera users in relation to duration of use $(6-24,27-48$ and 51-96 months) (Table 2).

\section{Magnitude and determinants of change in mean arterial pressure among study participants}

Table 3 revealed a non-significant difference $(\mathrm{p}=0.85)$ in the MAP between Depo-Provera users and control group. There was no significant difference in systolic blood pressure (SBP) and diastolic blood pressure (DBP) between Depo-Provera user $(108.4 \pm 12.47 ; 70.7 \pm 7.82)$ and controls (108.2 $\pm 11.00 ; 72.8 \pm 7.83)$. Furthermore, the change in MAP of Depo-Provera users and control

Table 1 Mean weight, BMI and MAP of Depo-Provera users

\begin{tabular}{|c|c|c|c|c|}
\hline $\begin{array}{l}\text { Variables } \\
(n=50)\end{array}$ & Mean $\pm(S D)$ & $\begin{array}{l}\text { Mean } \\
\text { differences }\end{array}$ & $\begin{array}{l}\text { Percentage } \\
\text { of change }\end{array}$ & $\mathrm{p}$-value \\
\hline \multicolumn{5}{|l|}{ Weight (Kg) } \\
\hline Weight after & $55.14 \pm 6.63$ & $1.6 \mathrm{~kg}$ & $+2.99 \%$ & $0.02^{*}$ \\
\hline Weight before & $53.54 \pm 6.42$ & & & \\
\hline \multicolumn{5}{|c|}{ Body mass index $\left(\mathrm{Kg} / \mathrm{m}^{2}\right)$} \\
\hline BMI after & $22.05 \pm 3.10$ & $0.67 \mathrm{~kg} / \mathrm{m}^{2}$ & $+3.13 \%$ & $0.02^{*}$ \\
\hline BMI before & $21.38 \pm 2.70$ & & & \\
\hline \multicolumn{5}{|c|}{ Mean arterial pressure $(\mathrm{mmHg})$} \\
\hline MAP after & $83.21 \pm 8.68$ & $0.51 \mathrm{mmHg}$ & $+0.62 \%$ & 0.67 \\
\hline MAP before & $82.70 \pm 7.56$ & & & \\
\hline
\end{tabular}

+ Increased from baseline; *statistically significant, p-values (obtained by paired t-test)
Table 3 Comparison of Depo-Provera user and non-user participants using independent t-test

\begin{tabular}{llllll}
\hline Variables & $\begin{array}{l}\text { Depo-Provera } \\
\text { users }(\mathbf{n = 5 0})\end{array}$ & $\begin{array}{l}\text { Control group } \\
(\mathbf{n}=\mathbf{5 0})\end{array}$ & \% & -value \\
\hline Age (years) & & & & & \\
$<20$ & 1 & 2 & 1 & 2 & 0.93 \\
$20-30$ & 39 & 78 & 40 & 80 & \\
$>30$ & 10 & 20 & 9 & 18 & \\
Total & 50 & 100 & 50 & 100 & \\
Duration of use of Depo-Provera (month) & & \\
$6-24$ & 23 & 46 & - & - & \\
$27-48$ & 21 & 42 & - & - & \\
$51-96$ & 6 & 12 & - & - & \\
Total & 50 & 100 & - & - & \\
Weight (Kg) & $55.14 \pm 6.62$ & - & $55.52 \pm 8.30$ & - & 0.80 \\
Height (m) & $1.58 \pm 0.65$ & - & $1.60 \pm 0.60$ & - & 0.09 \\
BMI (Kg/m $\left.{ }^{2}\right)$ & $22.05 \pm 3.10$ & - & $21.56 \pm 3.05$ & - & 0.42 \\
MAP (mmHg) & $83.22 \pm 8.68$ & - & $82.91 \pm 6.98$ & - & 0.85 \\
\hline
\end{tabular}

Variables statistically significant at $p \leq 0.05, p$-values (obtained by independent t-test)

group was not statistically significant $(\mathrm{p}=0.67)$. The mean SBP and DBP were $107 \pm 8.86 ; 70.6 \pm 8.18$ before and 108.4 $\pm 12.47 ; 70.7 \pm 7.82$ after they had been using Depo-Provera. This difference was not significant $(\mathrm{p}=0.41$ and $\mathrm{p}=0.94$, respectively). The present study found no association between the variables, weight (BMI) and blood pressure among the Depo-Provera users (Table 1).

\section{Discussion}

The finding of this study demonstrated that Depo-Provera users had significant weight gain and increased BMI as compared to their respective pretreatment value. This is in agreement with a prospective cohort study performed on 97 Brazilian women, aimed to compare body weight and body composition in Depo-Provera and

Table 2 Changes in mean weight and BMI of Depo-Provera users related to the duration of use

\begin{tabular}{|c|c|c|c|c|c|}
\hline Parameters & Duration (month) & $\mathrm{n}$ & Mean \pm SD & Percentage of change & p-value \\
\hline \multirow[t]{4}{*}{ Change in mean weight (Kg) } & $6-24$ & 23 & $1.78 \pm 5.06$ & +3.32 & \multirow[t]{4}{*}{0.96} \\
\hline & $27-48$ & 21 & $1.38 \pm 4.35$ & +2.58 & \\
\hline & $51-96$ & 6 & $1.66 \pm 5.24$ & +3.10 & \\
\hline & Total & 50 & $1.60 \pm 4.70$ & +2.99 & \\
\hline \multirow[t]{4}{*}{ Change in mean $\mathrm{BMI}\left(\mathrm{Kg} / \mathrm{m}^{2}\right)$} & $6-24$ & 23 & $0.76 \pm 2.12$ & +3.55 & \multirow[t]{4}{*}{0.95} \\
\hline & $27-48$ & 21 & $0.57 \pm 1.78$ & +2.67 & \\
\hline & $51-96$ & 6 & $0.65 \pm 2.15$ & +3.04 & \\
\hline & Total & 50 & $0.67 \pm 1.94$ & +3.13 & \\
\hline
\end{tabular}

+ Increased from baseline, p-values (obtained by one-way ANOVA) 
copper IUD users at baseline and after 1 year of use [11]. Another study, done to assess the association between progestin-only contraceptive use and changes in body weight, revealed that weight gain was greater in DepoProvera group than in the group using a non-hormonal IUCD, which is in agreement with the findings of the present study [12]. Another similar study showed that the use of Depo-Provera was associated with weight gain compared to the copper IUCD [9]. They also suggested that only the black race was associated with significant weight gain. The present study also supports the findings of other studies where the BMI of the Depo-Provera users was increased significantly than the control group and were in the overweight range [13]. Moreover, a recent study conducted to assess dietary intake and weight gain among adolescents on Depo-Provera, demonstrated that mean BMI increased significantly from $23.7 \pm 5.3$ at the baseline to $25.3 \pm 5.7$ after 12 months of using of Depo-Provera with increased mean percentage body fat significantly [14]. While other studies indicated Depo-Provera users pose increased body weight in comparison to their controls, however, changes were not statistically significant [6]. This could be due to the difference in race/ethnicity, which is associated with weight gain, where black women had a greater mean weight gain compared to white, Bushmen, oriental and Papuan with continued Depo-Provera use $[9,16]$. It can also be due to practicing physical exercise following good counseling of study participants in the previous study.

Increment of weight is a common phenomenon for women initiating hormonal contraceptives, especially Depo-Provera. However, the existing literature does not provide a clear-cut picture of the mechanism of DepoProvera-related weight gain. The previous authors tried to report the reasons why the use Depo-Provera can lead to weight increase. Self-reported increase of appetite after 6 months of Depo-Provera use was investigated by Le et al. [17]. This supports Leiman who reported that the weight gain among Depo-Provera users was related to their higher appetite and subsequently higher dietary ingestion as a result of modifications of the hypothalamic appetite control center by Depo-Provera. Contrary to the prior studies, the findings of Lange suggested that DepoProvera associated weight gain cannot be explained by a simple, direct relationship to the increased food consumption $[14,18]$. Therefore, the role of appetite and dietary intake for Depo-Provera-associated weight gain remains to be clarified.

The result obtained from the present study indicates that the Depo-Provera does not have unfavorable effect on blood pressure. The MAP, SBP and DBP between Depo-Provera users and the control group were not significantly different. Changes in MAP, SBP and DBP before and after they had been using Depo-Provera were not statistically significant. This finding was similar with the findings of other studies $[6,15]$. This study needs to be extended on wider population so as to generalize the effects of Depo-Provera on the health of Ethiopian women and further studies required to elucidate the molecular mechanism, if any which contribute to the change in body weight among women using Depo-Provera.

\section{Conclusion}

In conclusion, Depo-Provera users had significant weight gain and significant increase in BMI compared with their respective pretreatment value, although, these effects appeared to be independent of the duration of use of Depo-Provera. Women taking Depo-Provera did not show significant change in MAP compared to controls or to their respective pretreatment value, which indicates that Depo-Provera use does not have unfavorable effects on blood pressure.

\section{Limitation}

The possible limitation of this study is the use of small sample size. The other limitation lies in the fact that potential confounders like total daily caloric intake, physical activity and intake of cholesterol rich diets were not considered. In spite of the above limitation, this study tries to assess the possible association between DepoProvera use and possible weight gain, which is a risk factor for different chronic diseases. So it gives insight for policy makers in considering this effect and to look for other possible solutions.

\section{Abbreviations}

MAP: mean arterial pressure; SBP: systolic blood pressure; DBP: diastolic blood pressure; IUCD: intrauterine contraceptive device; BMI: body mass index.

\section{Acknowledgements \\ The authors' great gratitude goes to all the nurses working in Azezo Health Center for their technical support during the data collection, and to all study participants who have voluntarily participated in the research. Finally, the authors' heartfelt thanks go to the University of Gondar for its administrative support in realizing this research.}

\section{Authors' contributions}

MF collected data, designed the study, performed analysis and interpretation of data. YY supervised the data collection, analysis, interpretation of data. TM, YMF, TB drafted the manuscript. All authors read and approved the final manuscript mutually.

\section{Funding}

Funding was provided by College of Medicine and Health Sciences, University of Gondar (Grant no. Uog/11/027).

Availability of data and materials

The data could be accessed by a request to the corresponding author. 


\section{Ethics approval and consent to participate}

Ethical clearance of this study was obtained from Ethical Review Board of University of Gondar with the protocol number of GCMH71/2017. Written informed consent was also taken from each study participant.

\section{Consent to publish}

Not applicable.

\section{Competing interests}

Authors declare that they have no conflict of interest.

\section{Author details}

1 Department of Biochemistry, School of Medicine, College of Medicine and Health Sciences, University of Gondar, Gondar, Ethiopia. ${ }^{2}$ Nursing Department, College of Medicine and Health Sciences, University of Gondar, Gondar, Ethiopia. ${ }^{3}$ Department of Physiology, School of Medicine, College of Medicine and Health Sciences, University of Gondar, Gondar, Ethiopia.

Received: 12 June 2019 Accepted: 10 August 2019

Published online: 15 August 2019

\section{References}

1. Mohammed A, Woldeyohannes D, Feleke A, Megabiaw B. Determinants of modern contraceptive utilization among married women of reproductive age group in North Shoa Zone, Amhara Region, Ethiopia. J Reprod Health. 2014;11(13):1-7.

2. Central Statistical Agency. Ethiopia mini demographic and health survey. Addis Ababa: Central Statistical Agency; 2015.

3. World population data sheet. Population Reference Bureau. 2015.

4. United Nations. World contraceptive use. New York: UN department of economic and social affairs, Population Division; 2007.

5. United Nations. World contraceptive patterns. New York: UN department of economic and social affairs, Population Division; 2013.

6. Al-Youzbaki WB. C-reactive protein and lipid profile among depomedroxyprogesterone acetate injections users. J Ann Coll Med Mosul. 2011;37(2):48-56.

7. Prata N, Weidert K, Fraser A, Amanuel Gessessew A. Meeting rural demand: a case for combining community-based distribution and social marketing of injectable contraceptives in Tigray, Ethiopia. PLoS ONE. 2013;8(7):1-8
8. Bonny AE, Lange HLH, Rogers LK, Gothard DM, Reed MD. A pilot study of depot medroxyprogesterone acetate pharmacokinetics and weight gain in adolescent females. Contraception. 2014;89(5):357-60.

9. Vickery Z, Madden T, Zhao Q, Secura G, Allsworth JE, Peipert JF. Weight change at 12 months in users of three progestin-only contraceptive methods. Contraception. 2013;88(4):503-8.

10. Xiang AH, Kawakubo M, Buchanan TA, Kjos SL. A longitudinal study of lipids and blood pressure in relation to method of contraception in Latino women with prior gestational diabetes mellitus. Diabetes Care. 2007;30(8):1952-8.

11. Dal'Ava N, Bahamondes L, Bahamondes MV, Bottura BF, Monteiro I. Body weight and body composition of depot medroxyprogesterone acetate users. Contraception. 2014;90:182-7.

12. Lopez LM, Edelman A, Chen M, Otterness C, Trussell J, Helmerhorst FM. Progestin-only contraceptives: effects on weight. Cochrane Database Syst Rev. 2013;2(7):1791-802.

13. Asare GA, Santa S, Ngala RA, Asiedu B, Afriyie D, Amoah AGB. Effect of hormonal contraceptives on lipid profile and the risk indices for cardiovascular disease in a Ghanaian community. Int J Women's Health. 2014:6:597-603.

14. Lange HL, Belury MA, Secic M, Thomas A, Bonny AE. Dietary intake and weight gain among adolescents on depot medroxyprogesterone acetate. J Pediatr Adolesc Gynecol. 2015;28:139-43.

15. Taneepanichskul S, Reinprayoon D, Jaisamrarn U. Effects of DMPA on weight and blood pressure in long-term acceptors. Contraception. 1999;59(5):301-3.

16. Enk L, Landgren BM, Lindberg UB, Silfverstolpe G, Crona N. A prospective, one-year study on the effects of two long acting injectable contraceptives (depot-medroxyprogesterone acetate and norethisterone oenanthate) on serum and lipoproteins. Horm Metab Res. 1992;24(2):85-9.

17. Le $Y L$, Rahman M, Berenson BA. Early weight gain predicting later weight gain among Depo-medroxyprogesterone acetate users. Obstet Gynecol. 2009;114:279-84.

18. Leiman G. Depo-medroxyprogesterone acetate as a contraceptive agent: its effect on weight and blood pressure. Am J Obstet Gynecol. 1972;114:97-102.

\section{Publisher's Note}

Springer Nature remains neutral with regard to jurisdictional claims in published maps and institutional affiliations.
Ready to submit your research? Choose BMC and benefit from:

- fast, convenient online submission

- thorough peer review by experienced researchers in your field

- rapid publication on acceptance

- support for research data, including large and complex data types

- gold Open Access which fosters wider collaboration and increased citations

- maximum visibility for your research: over $100 \mathrm{M}$ website views per year

At BMC, research is always in progress.

Learn more biomedcentral.com/submissions 